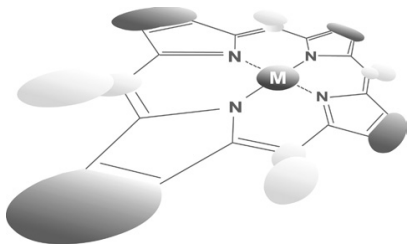

\title{
The kinetic studies of the solvent-promoted aggregation of a steroid-porphyrin derivative
}

\author{
Mario L. Naitana ${ }^{\mathrm{a}}$, Mykhaylo Dukh ${ }^{\mathrm{b}}$, Karel Zelenka ${ }^{\mathrm{c}}$, Tomáš Trnka ${ }^{\mathrm{c}}$, \\ Mariano Venanzi ${ }^{a}$, Raffaella Lettieri ${ }^{a}$, Pavel Drašar ${ }^{b}$ and Donato Monti ${ }^{\star a}$ \\ ${ }^{a}$ University of Rome Tor Vergata, Department of Chemical Technologies, Via della Ricerca Scientifica 1, \\ 00133 Rome, Italy \\ ${ }^{\mathrm{b}}$ Department of Natural Compounds Chemistry, Institute of Chemical Technology Prague, Technická 5 , \\ 16628 Prague 6, Czech Republic \\ ${ }^{c}$ Department of Organic Chemistry, Charles University Prague, Albertov 2030, 12840 Prague 2, Czech Republic
}

Dedicated to Professor Evgeny Luk'yanets on the occasion of his 75th birthday

Received 23 October 2012

Accepted 11 June 2013

\begin{abstract}
The study of the aggregation of a steroid-functionalised porphyrin derivative shows the formation of chiral suprastuctures. Kinetic studies indicate that the mechanism of the aggregation strongly depends on both the nature of the media and on the concentration of the tetrapyrrolic macrocycle.
\end{abstract}

KEYWORDS: porphyrinoids, steroids, reaction mechanisms, chirality, supramolecular chemistry.

\section{INTRODUCTION}

The self-assembly properties of porphyrin derivatives and their related macrocycles are the focus of challenging researches devoted to the achievement of suprastructures with application in material chemistry [1], and sensors field [2]. Within these topics we focused on the aggregation properties of porphyrin derivatives characterised by the presence of chiral polar functionalities, with the aim to build up mesoscopic structures featuring supramolecular chirality [3]. In particular, we devoted our interest in (L)-proline [4], glucosides [5], or steroid derivatives [6] as structural chiral effectors, which, besides inferring to the macrocycle amphiphilic properties, drive the stereochemical evolution toward the formation of specific architectures. These latter structures are also of importance in the study of their interaction with liposomes as cell-membrane mimics [7], for the development of drug carriers in photodynamic treatment of cancer and related diseases (PDT) [8]. Morover, steroid receptors (i.e. cholapod) have been found to feature excellent affinities

*Correspondence to: Donato Monti, email: monti@stc. uniroma2.it, fax: +39067259 toward anions, often accompanied by good selectivity [9]. It has been recently reported that porphyrin-steroid conjugates self-assemble in micelle-like nanoparticles, featuring interesting properties as molecular receptors for nitrogen based organic ligands [10].

In this work we wish to report on our studies on the aggregation properties of a tetra-steroid porphyrin derivative in aqueous organic solvent mixtures. The results obtained will be of importance for the possible application of these derivatives in pharmaceutical and medicinal chemistry, owing to the presence of cellular membrane affine steroid groups. These studies would also be of importance in the field of chiral materials [11], for sensing application, [12] and stereoselective catalysis [13].

\section{RESULTS AND DISCUSSION}

We entailed a detailed UV-visible and Circular Dichroism spectroscopic investigation on the self-recognition properties of a steroid-functionalised porphyrin derivative. The structure chosen, prepared according to the procedure published in our earlier paper [14] was a 5,10,15,20-tetrakis[ $3 \alpha, 7 \alpha, 12 \alpha$-tris(methoxymethoxy)53-cholan-24-yl]-porphyrin $\left(\mathbf{H}_{\mathbf{2}} \mathbf{T C h o l P}\right)$ (Chart 1), an 


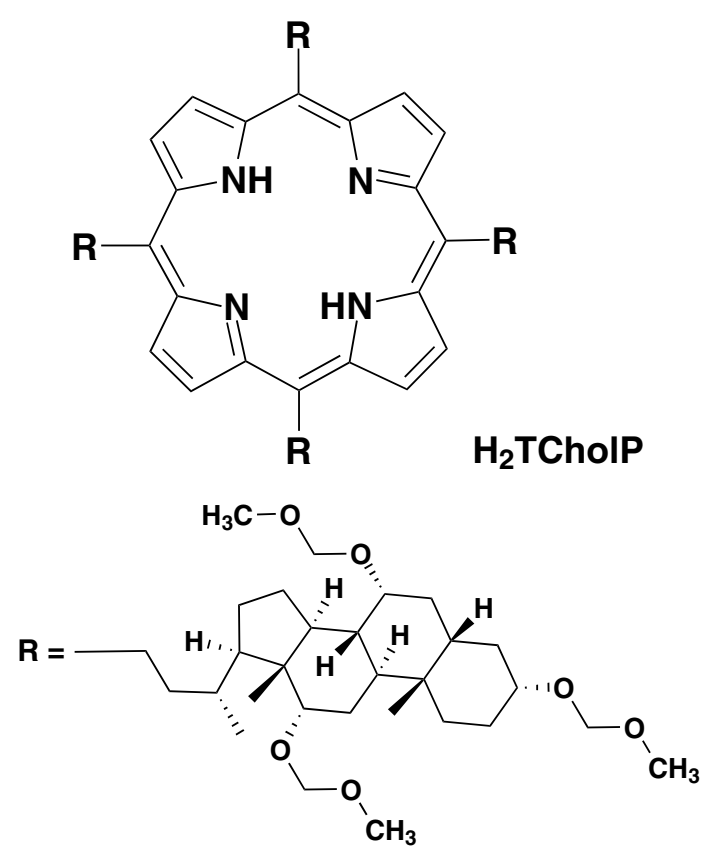

Chart 1. Molecular structure of porphyrin studied in this work

$\mathrm{A}_{4}$ type macrocycle bearing four meso-steroid moieties. Its amphiphilic character was endowed by the presence of the four oligooxamethylene chains, allowing to appreciable solubility in aqueous solvent mixtures.

Namely, the aggregation studies have been performed in dimethyl acetamide (DMAC) and in dimethyl sulfoxide (DMSO) aqueous solvent mixtures, to compare the effect of the solvent properties on the propensity of the macrocycles to yield defined supramolecular architectures. Such solvent combinations have been found to give the best performances in terms of solubility, stability of the title porphyrin solutes, and reproducibility of the results, with respect to other investigated hydroorganic media such as ethanol/water, acetonitrile/water, or tetrahydrofurane/water (results not reported).

In pure DMAC the derivative $\mathbf{H}_{\mathbf{2}}$ TCholP features a sharp Soret band at $419 \mathrm{~nm}$, indicating that the macrocycle is present in solution in its monomeric form. Analogous behavior has been featured in DMSO, with the only difference that the Soret absorption maximum is somewhat shifted to $420 \mathrm{~nm}$.

In mixed aqueous-organic solvent media, the increase of water proportion triggers the aggregation of the monomers, toward the formation of porphyrin aggregates, as indicated by the typical spectroscopic UV-vis changes (hypochromicity, band broadening, and wavelength shift, Fig. 1). It is noteworthy that the presence of clear isosbestic points suggests that the process occurs with the formation of defined supramolecular structures. The critical solvent composition at which the aggregation is onset, as well as its extent at equilibrium, depend somewhat on the nature of the organic co-solvent. In DMAC/water, for example, the aggregation is complete

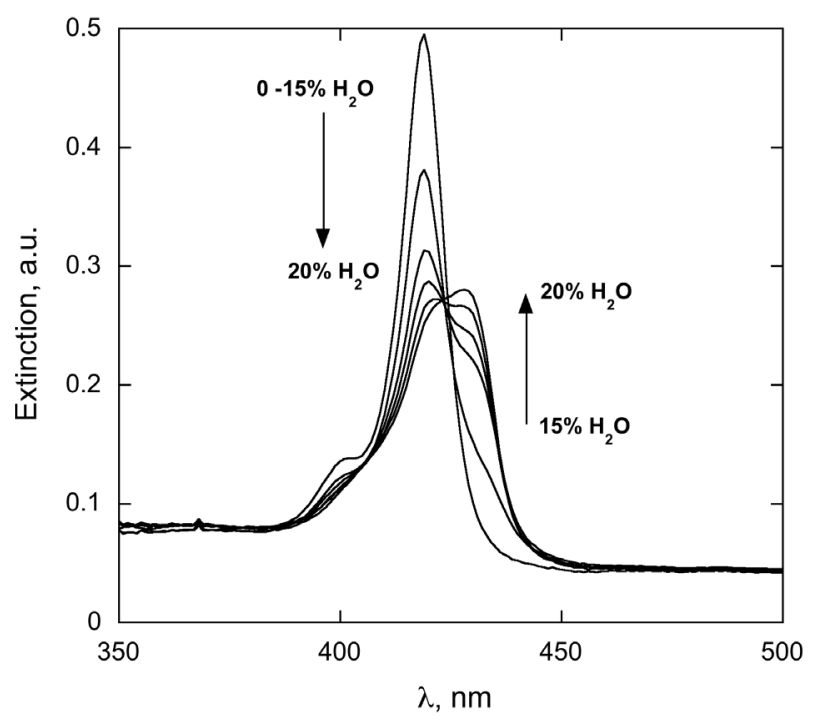

Fig. 1. UV-vis spectra changes of $\mathbf{H}_{2}$ TCholP $(2.2 \mu \mathrm{M})$ in DMAC/water solvent mixtures, upon increasing water proportion

within $20 \%$ of water, with Soret band of the aggregates found at $427 \mathrm{~nm}$. In the DMSO/water counterpart, the formation of aggregates is complete at earlier $15 \%$ of water content, with the Soret band shifted to $430 \mathrm{~nm}$, reflecting the small differences found for the monomeric states. In both of the cases, a clear formation of J-type species is shown, as indicated by the typical red shift of the porphyrin spectral pattern. The bulk composition largely affects the rate of the aggregate formation; detailed kinetic studies will be reported and discussed in a next section.

Circular Dichroism Spectroscopy studies gave interesting insights on the self-recognition properties of the title derivative. A CD spectrum of $\mathbf{H}_{\mathbf{2}} \mathbf{T C h o l P}$, in pure DMAC features a weak negative band at $419 \mathrm{~nm}$ $\left([\theta]=-2.5 \times 10^{4}\right.$ deg. $\left.\mathrm{cm}^{2} . \mathrm{dmol}^{-1}\right)$ (Fig. 2a), which should be safely interpreted on the basis of the induction effect of the bulky chiral substituent on the $\mathrm{B}$ electronic transition dipole (Soret band) [15], and on the effect of the porphyrin frame distortion from planarity. When the studies are carried out under aggregative conditions (see Experimental section), the aggregation lead to the formation of chiral suprastructures, featuring clear bisignated, negative, $\mathrm{CD}$ bands, indicating a "counterclockwise" mutual disposition of electronically coupled macroccycles. On the basis of the excitonic theory, the sign of the $\mathrm{CD}$ spectrum is related to the absolute configuration of the interacting chromophores. A positive sign of the first band indicate a clockwise arrangement (P-configuration), whereas a negative sign indicates a counter-clockwise arrangement (M-configuration), as graphically reported in ESI [16]. The final CD intensities are proportional to the bulk porphyrin concentration within the investigated 1.5 to $5.0 \mu \mathrm{M}$ range, with the 


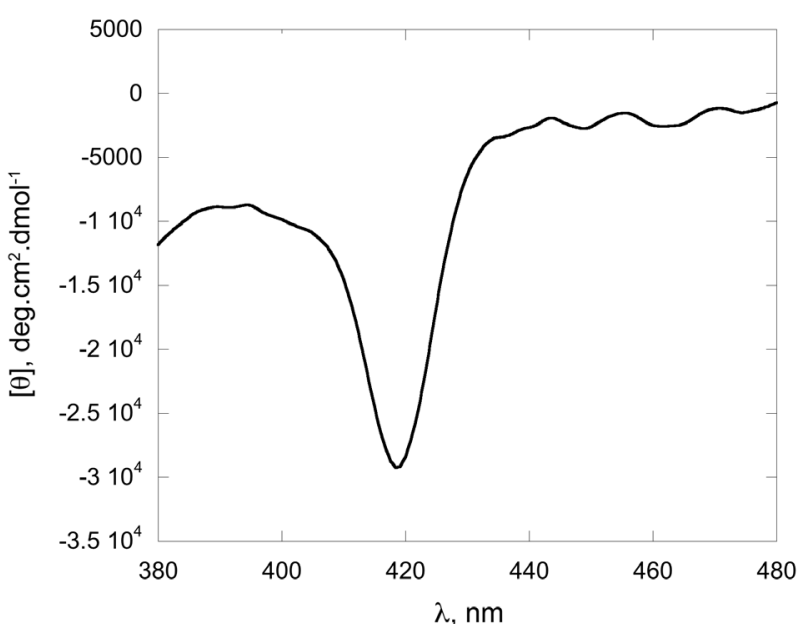

(a)

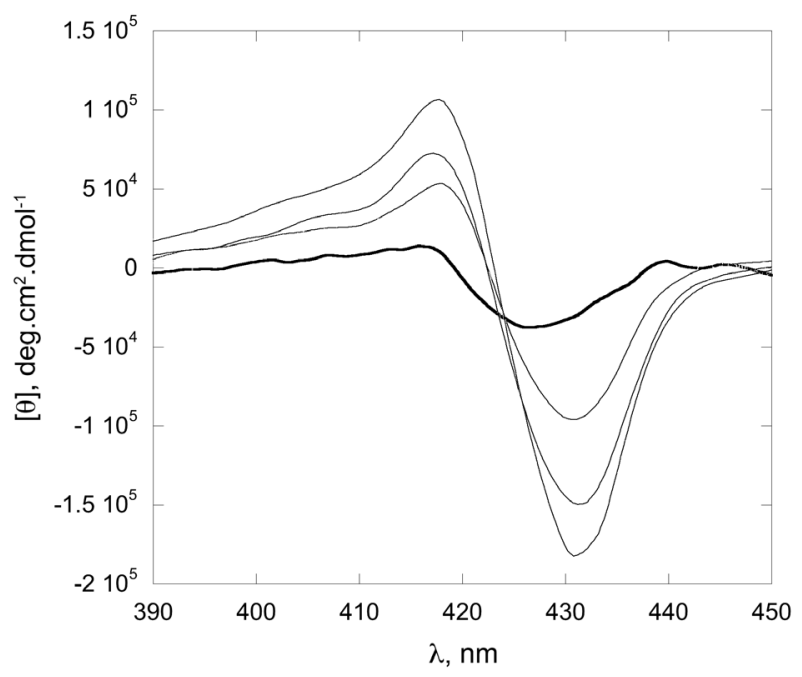

(b)

Fig. 2. CD spectra of $\mathbf{H}_{2}$ TCholP $(2.0 \mu \mathrm{M})$ in DMAC (a), and in DMAC/water (84/16 v:v) mixture (b), upon increasing porphyrin concentration $(1.2-4.5 \mu \mathrm{M})$

molar ellipticity spanning in the range of $\theta \approx 10^{5} \mathrm{deg}$. $\mathrm{cm}^{2}$. dmol ${ }^{-1}$, with a constancy of the crossover point at $c a$. $426 \mathrm{~nm}$ (Fig. 2b), corresponding to the maximum of the Soret band featured in the same conditions. This finding can be interpreted on the basis of a closer interaction, by increasing the porphyrin concentration, with the overall symmetry of the mesoscopic structures remaining unchanged.

The studies carried out in DMSO/water mixtures show some similarities with the results obtained in the former media. Under non-aggregative conditions (i.e. neat DMSO solutions), CD spectra show a weak negative band at $c a .430 \mathrm{~nm}$, hardly disentangled from the background noise. Also in this case, at higher water proportion, the formation of the aggregates is accompanied by a growth of negative bisignated bands with constant crossover point at $c a .428 \mathrm{~nm}$, as a consequence of observed small UV-vis solvotropic shift. This finding indicates that the different solvation properties of the media do not affect the stereochemistry of the aggregation process.

\section{Kinetic studies}

Kinetic studies on the aggregation of the title porphyrin derivative have been performed in order to shed light on the intimate nature of the aggregation mechanism. The aggregation has been carried out in the optimal solvent conditions that allows for UV-vis spectroscopy changes that can be conveniently followed by conventional means. All the reactions featured clean isosbestic points. A close analysis of the kinetic behavior showed remarkable features of the self-assembly process depending on the actual reaction conditions. The aggregation properties, in terms of rate constant values and mechanism, are strongly influenced by the starting porphyrin concentration and on the nature of the organic co-solvent (i.e. DMAC vs. DMSO). By carrying out the aggregation process in DMAC/water 84/16 (v:v) at low concentration (i.e. 1.25 to $3.15 \mu \mathrm{M}$ ), a typical sigmoidal profile with an initial lag period is observed. A similar feature was observed by several authors who considered this lag phase of initial self-interaction as a kinetically relevant step, in which critical nucleation centers are formed composed by a definite number of macrocycles, that catalyse the further growth of the supramolecular structures [17]. The observed kinetic features can be by an autocatalytic behavior, with the likely formation of fractal-type species (Fig. 3a).

The decay could be conveniently fitted with the following well-known model, which has been widely used in related studies on porphyrin aggregation:

$$
\begin{aligned}
& \left(\mathrm{Ext}_{\mathrm{t}}-\mathrm{Ext}_{\infty}\right) /\left(\mathrm{Ext}_{0}-\mathrm{Ext}_{\infty}\right) \\
& \quad=\left(1+(\mathrm{m}-1)\left[k_{0} \mathrm{t}+(\mathrm{n}+1)^{-1}\left(k_{c} \mathrm{t}\right)^{\mathrm{n}+1}\right]\right)^{1 /(\mathrm{m}-1)}
\end{aligned}
$$

In this equation, $\mathrm{Ext}_{0}, \mathrm{Ext}_{\infty}$, and $\mathrm{Ext}_{\mathrm{t}}$ are the extinction values at the initial, final, and given time [18]. The kinetic parameters have the usual meaning, being $k_{0}$, and $k_{c}$ referred to the "uncatalyzed" and "catalyzed" rates, $m$ is the nucleation factor (i.e. the minimum aggregated porphyrin monomers acting as a "nucleation seeds," formed during the first delay period), and $n$ is the fractal growth factor, respectively. A value of $n>1$ means the occurrence of a cooperative catalysed aggregate growth. In this equation, contrary to classical kinetic treatment, the "catalyzed" rate constant is regarded as time dependent. A regression fit, according to the proposed model (see Experimental section for details), gave the parameters $k_{0}$ with mean value of $1.6 \times 10^{-3} \mathrm{~s}^{-1}, k_{c}$ ranging within 6 to $30 \times 10^{-3} \mathrm{~s}^{-1}, m$ mean values ranging between 7 and 10 , and $n$ spanning within 3 and 8 (Table 1). As shown in the table, the data at lower concentration are affected by a high experimental error, due to very small absorption changes, and this infers the quality of the corresponding fit. Remarkably, on further increasing the concentration 


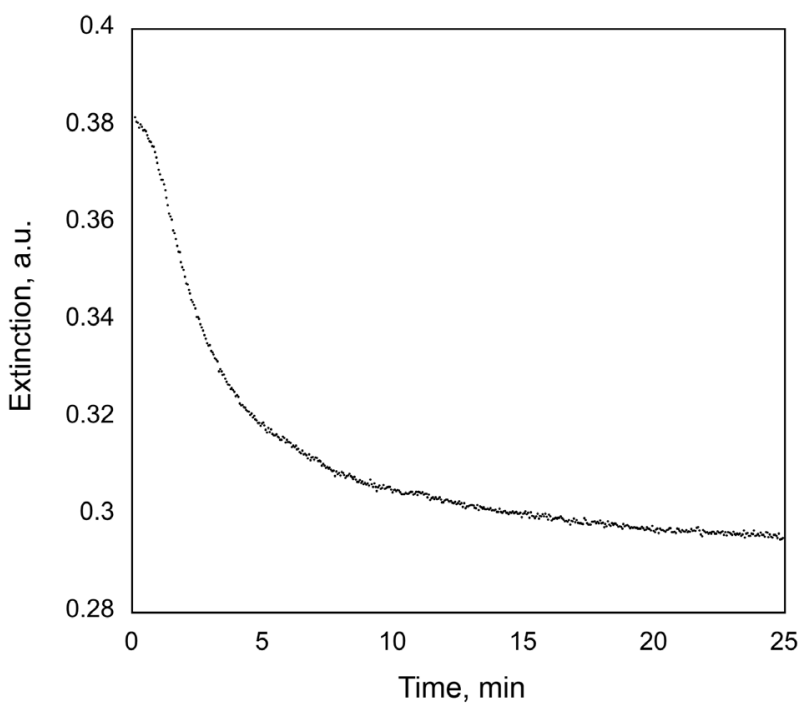

(a)

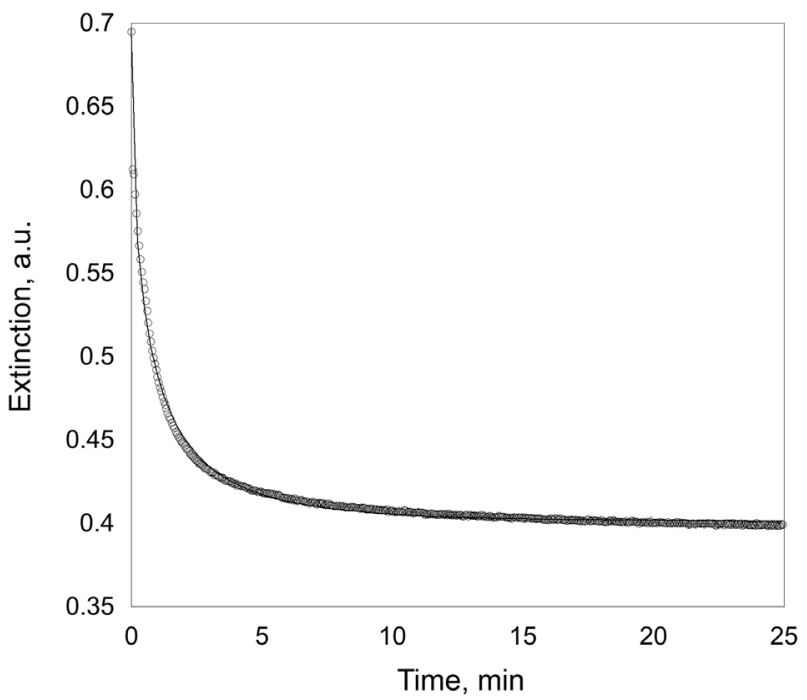

(b)

Fig. 3. Kinetic plot for the aggregation of $\mathbf{H}_{2} \mathbf{T C h o l P}$ in DMAC/ water mixture $(84 / 16, \mathrm{v}: \mathrm{v} ; \lambda=419 \mathrm{~nm}, 298 \mathrm{~K})$ at $1.26 \mu \mathrm{M}$ (a) and $3.41 \mu \mathrm{M}$ (b)

of porphyrinic substrate up to $c a .4 \mu \mathrm{M}$, a change in mechanism toward a diffusion-limited aggregation process (DLA) is observed [19]. This specific term is related to the statistical growth of particle cluster of fractal dimentions, the only (or at least the main) physical vector being the monomer transport through the solvent [19c]. It must be pointed out that this molecular process is driven by the usual activation energy values, and that is not diffusion controlled; i.e. not every molecular encounter is a reactive event, and the rates may depend on the properties of the medium (i.e. polarity, viscosity).

The spectroscopic variations (decay of Soret band intensity at $419 \mathrm{~nm}$; Fig. 3b) can be fitted by a "stretched exponential" equation (Equation 2).

$$
\mathrm{Ext}_{\mathrm{t}}=\mathrm{Ext}_{0}+\left(\mathrm{Ext}_{\infty}-\mathrm{Ext}_{0}\right)\left[1-\exp (-k \mathrm{t})^{n}\right]
$$

In this equation $k$ is the apparent first-order aggregation rate constant, and $n$ is the stretching factor, which modulates the diffusion-limited growth of the aggregates that in this kind of mechanism is required to be $n<1$. This kinetic behavior implies the initial rapid formation of small porphyrin clusters (nucleation seeds) subsequently growing by slow inclusion of diffusing porphyrin monomers. Evidently this latter pathway is biased at high monomer concentration, in which the nucleation phase would no longer constitute the rate-determining step. The corresponding parameters are reported in Table 1, indicating a moderate further increase of the apparent rate constant, and a virtual constancy of the $n$ factor values of about 0.5 . This behavior is graphically represented in Fig. 4.

The optimal solubility featured by $\mathbf{H}_{\mathbf{2}} \mathbf{T C h o l P}$ in DMSO allowed for further studies of the aggregation mechanism in its aqueous solvent mixtures, in order

Table 1. Kinetic parameters ${ }^{\mathrm{a}}$ for the aggregation of $\mathbf{H}_{2} \mathbf{T}$ CholP, in DMAC/water 84/16 (298 K) at varying porphyrin concentration

\begin{tabular}{lccrl}
\hline$[\mathbf{P}], \mu \mathrm{M}$ & $k_{d} / 10^{-3} \mathrm{~s}^{-1}$ & $k_{c} / 10^{-3} \mathrm{~s}^{-1}$ & \multicolumn{1}{c}{$m$} & $n$ \\
\hline 1.26 & $5(2)$ & $5.9(0.1)$ & $12.4(0.2)$ & $2.63(0.04)$ \\
1.44 & $1.6(0.5)$ & $8.02(0.07)$ & $6.9(0.1)$ & $1.32(0.04)$ \\
1.79 & $1.5(0.3)$ & $12.8(0.1)$ & $7.5(0.1)$ & $2.59(0.06)$ \\
2.45 & $1.6(0.1)$ & $25.0(0.1)$ & $10.3(0.4)$ & $8.0(0.4)$ \\
3.15 & $3.5(0.2)$ & $30.6(0.1)$ & $11.0(0.4)$ & $7.8(0.3)$ \\
$3.41^{\mathrm{b}}$ & & $23.6(0.4)$ & & $0.55(0.01)$ \\
$3.98^{\mathrm{b}}$ & & $31.5(0.4)$ & & $0.54(0.01)$ \\
\hline
\end{tabular}

${ }^{\mathrm{a}}$ Fit calculated by Eq. 1. ${ }^{\text {b}}$ Fit calculated by Eq. 2. Uncertainties are reported in parentheses.

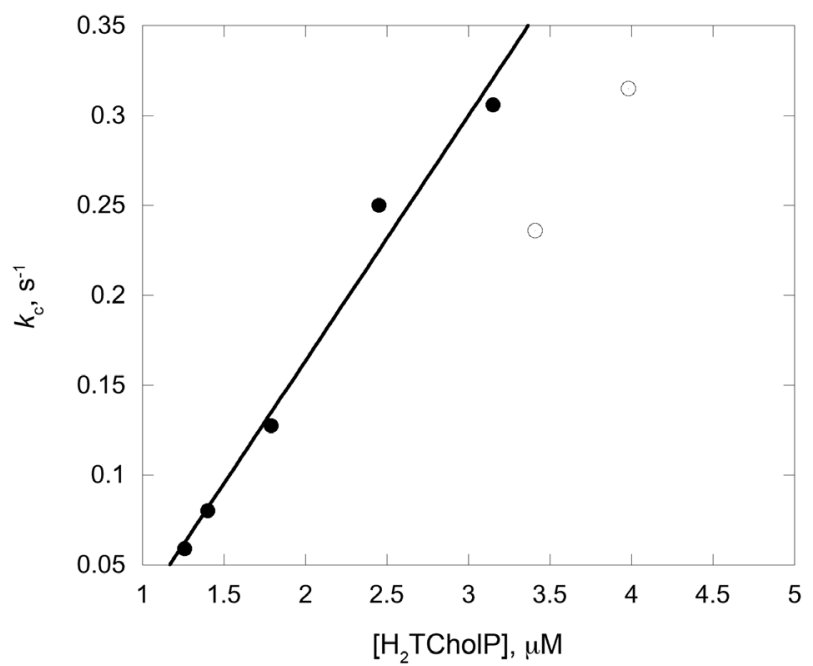

Fig. 4. Catalyzed rate constant $k_{c}$ vs. porphyrin concentration, for the aggregation of $\mathbf{H}_{2}$ TCholP in DMAC/water 84/16 (v:v). (•) Values calculated by Eq. 1 ; (O) values calculated by Eq. 2 
to evaluate the effect of the media on the aggregation parameters. The most suitable solvent composition has been found in this case to be DMSO/water 92/8 (v:v). In these conditions, a DLA behavior has been found throughout the concentration window investigated (i.e. 1.4 to $3.8 \mu \mathrm{M}$ ). The data are reported in Table 2 and graphically represented in Fig. 5a. It is of note that the $k_{a p p} v s$. concentration plot showed a clear discontinuity at concentration above $2.5 \mu \mathrm{M}$, likely due to a change toward a different type of mechanism. The increase of reactivity is associated to a strong reduction of the aggregation stretching parameter $n$ (Fig. 5b). This would be tentatively ascribed to a change in

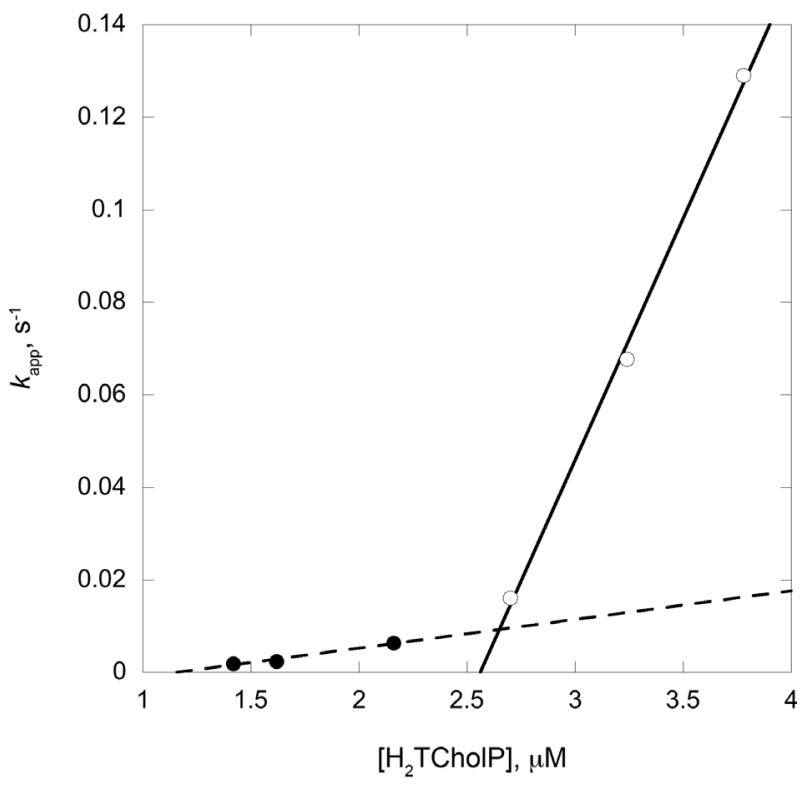

(a)

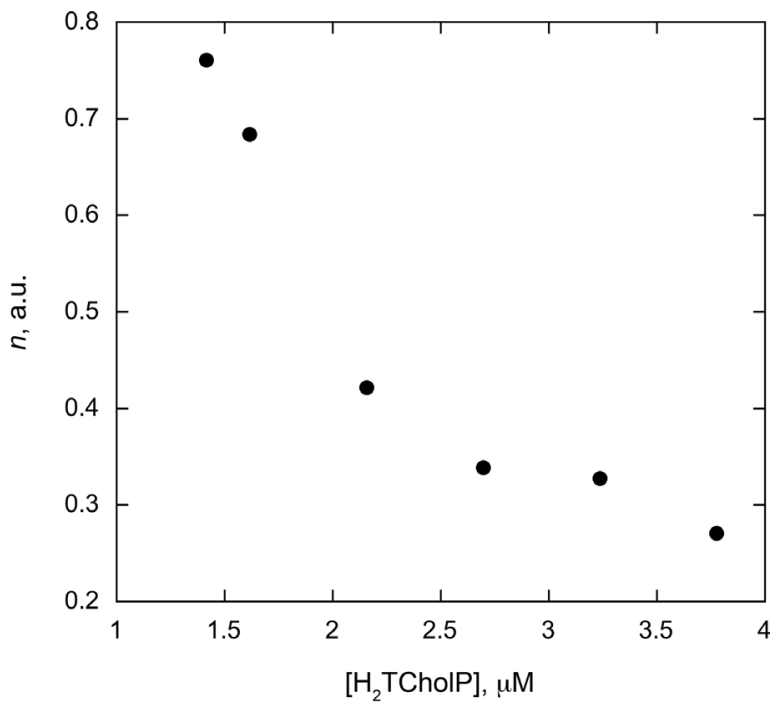

(b)

Fig. 5. Plot of kinetic parameters $k_{a p p}$ (a) and $n$ (b) $v s$. porphyrin concentration, for the aggregation of $\mathbf{H}_{2}$ TCholP in DMSO/ water 92/8 v:v (298 K)
Table 2. Kinetic parameters ${ }^{\mathrm{a}}$ for the aggregation of $\mathbf{H}_{2}$ TCholP, in DMSO/water 92/8 v:v $(298 \mathrm{~K})$ at different porphyrin concentration

\begin{tabular}{lcc}
\hline$[\mathrm{P}], \mu \mathrm{M}$ & $k_{\text {app }} / 10^{-3} \mathrm{~s}^{-1}$ & $n$ \\
\hline 1.42 & $1.9(0.1)$ & $0.76(0.04)$ \\
1.62 & $2.4(0.2)$ & $0.68(0.04)$ \\
2.16 & $6.3(0.5)$ & $0.42(0.02)$ \\
2.70 & $16.1(0.2)$ & $0.34(0.01)$ \\
3.24 & $67.7(0.8)$ & $0.33(0.01)$ \\
3.78 & $129(6)$ & $0.27(0.01)$ \\
\hline
\end{tabular}

${ }^{a}$ Fit calculated by Eq. 2. Uncertainties are reported in parentheses.

mechanism in which the rate-limiting step for the formation of the suprastructures is the collapse of fastformed aggregated nuclei, and no longer their growth by inclusion of monomers [20]. Further investigations are needed to confirm this notion.

An evaluation of the reactivity in the two solvents examined, by comparing similar concentration ranges and assuming a similar aggregation mechanism, reveals substantially higher rates in DMSO/water mixture. This effect can be related to the higher general polarity of DMSO with respect to DMAC counterpart, being $\varepsilon_{0}: 37.8$

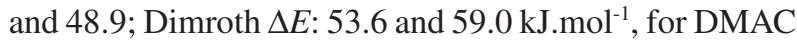
and DMSO, respectively. The fact that the aggregation is faster in a more polar solvent corroborates the hypothesis that the aggregation is fostered primarily by hydrophobic effects [21].

\section{EXPERIMENTAL}

\section{Synthesis of porphyrin compounds}

Porphyrin derivative has been prepared by following published procedures [14]. All analytical data are in full agreement to the proposed structure.

\section{Spectroscopic studies}

UV-vis spectroscopic measurements were performed on a Varian Cary $1 \mathrm{E}$ at room temperature, at porphyrin concentrations used within 1.5 to $5.0 \times 10^{-6} \mathrm{M}$, unless otherwise indicated. Solutions suitable for the aggregation studies were prepared as follows. Proper aliquots $(15 \div 150 \mu \mathrm{L})$ of a millimolar stock solution of porphyrin in dimethyl acetamide (DMAC) or dimethyl sufoxide (DMSO), were added to a proper amount of solvent in an $8 \mathrm{~mL}$ glass vial. To this solution the required amount of water were then added, to give $4.0 \mathrm{~mL}$ of resulting solution with the desired water/organic solvent proportion, with porphyrin concentrations varying within 1.5 to $5.0 \mu \mathrm{M}$ concentration range, unless otherwise indicated. 
A ca. $2.5 \mathrm{~mL}$ portion was transferred in a quartz cuvette and the relative UV-vis spectra acquired. The corresponding absorbance vs. solvent composition (i.e. water \%) plots indicate the critical composition at which the aggregation occurs. Spectra were further acquired at different time in order to get indications on the proper solvent mixture to be used for addressed kinetic experiments. CD spectra have been performed on a JASCO J-600, equipped with a thermostatted cell holder at $298 \mathrm{~K}$, and purged with ultra-pure nitrogen gas. The samples were prepared by following the above described procedure used for UV-vis studies.

\section{Kinetic studies}

Kinetic experiments were performed on a Varian Cary $1 \mathrm{E}$ Spectrophotometer equipped with a thermostating apparatus, by measuring the UV-vis spectroscopic changes (Soret B-band) of porphyrin derivatives with time. Porphyrin aqueous solutions, suited for kinetic studies, were prepared as follows. Proper aliquots of a millimolar stock solution of porphyrin in DMAC or DMSO (15 : $150 \mu \mathrm{L}$ ), were added to a proper amount of organic solvent. To this solution, the proper amount of water was then added, to ensure a required organic/water (v:v) mixtures with final porphyrin concentrations varying in the range of 1.4 to $4.0 \mu \mathrm{M}$. A suitable portion $(c a .2 .5 \mathrm{~mL}$ ) was rapidly transferred in a quartz or optical glass cuvette, and the relative UV-vis spectra acquired, with time. In the case of faster reactions (higher porphyrin concentrations) the solutions were prepared directly in the measure cuvette. The stock solutions were stored at $c a .4^{\circ} \mathrm{C}$, always pretreated by filtration through nylon syringe filters (Albet ${ }^{\circledR}$ $0.45 \mu \mathrm{m}$ diameter), and used within a week of preparation. Values of $k$ were obtained by analysing the absorbance (extinction) $v s$. time data points by the described equations (see text). The kinetic parameters were obtained by nonlinear least-squares regression fit (Kaleidagraph $^{\circledR}$ program, Synergy Software, 2003) over hundreds of experimental data points. The quality of the fits is generally very good, with $R^{2} \geq 0.9994$. In the case of faster reactions, the "zero-time" input values have been calculated by measuring the absorbance under non-aggregative conditions (i.e. solutions with higher organic solvent contents closer to that employed for kinetic experiments). The non-linear regressions were run accordingly, to give the other kinetic parameters, with the least calculated errors. Final regressions were then made with "free" zerotime parameters; the calculated values for Ext $\omega_{\infty}$ and $E x t_{0}$ were found to be always in excellent agreement with the experimental values. Data reported are the average values of at least two different runs with uncertainties within $5 \%$.

\section{CONCLUSION}

The aggregation properties of a steroid-functionalised porphyrin derivative have been studied by means of several UV-vis and CD spectroscopy. The results show that the self-interaction of the title macrocycle yields structures featuring supramolecular chirality, inferred by the presence of the chiral steroid groups. Addressed kinetic studies reveal peculiar mechanistic behavior, depending on the nature of the solvent and on the concentration of the substrate.

\section{Acknowledgements}

This work was supported by the Ministry of Education, Youth and Sports of the Czech Republic, Project No. MSM6046137305, by the Czech Science Foundation (Grant Agency of the CR), Project Nos. 304/10/1951 and P503/11/0616, and by the MIUR (Italy), PRIN 2009-Z9ASCA. We would like to thank Prof. Luigi Monsù Scolaro (Univ of Messina, Italy) for helpful discussion.

\section{Supporting information}

A schematic drawing of the different configuration of the porphyrin macrocycles is reported in Figure $\mathrm{S} 1$ in the supplementary material. This material is available free of charge via the Internet at http://www.worldscinet.com/ jpp/jpp.shtml.

\section{REFERENCES}

1. a) Drain ACM, Varotto A and Radivojevic I. Chem. Rev. 2009; 109: 1630. b) Elemans JAAW, van Hameren R, Nolte RJM and Rowan AE. Adv. Mat. 2006; 18: 1251.

2. Paolesse R, Monti D, Nardis S and Di Natale C. In Handbook of Porphyrin Sciences, Vol. 12, Kadish KM, Smith KM and Guilard R. (Eds.) World Scientific: London, 2010, Chapter 54, pp 121.

3. a) Crego-Calama M and Reinhoudt DN. In Supramolecular Chirality, Top. Curr. Chem. Springer: Berlin, 2006. b) Mateos-Timoneda MA, CregoCalama M and Reinhoudt DN. Chem. Soc. Rev. 2004; 33: 363. c) Cornelissen JJLM, Rowan AE, Nolte RJM and Sommerdijk NAJM. Chem. Rev. 2001; 101: 4039.

4. a) Monti D, Cantonetti V, Venanzi M, Ceccacci F, Bombelli C and Mancini G. Chem. Comm. 2004; 972. b) Monti D, Venanzi M, Mancini G, Di Natale C and Paolesse R. Chem. Comm. 2005; 2471. c) Monti D, Venanzi M, Stefanelli M, Sorrenti A, Mancini G, Di Natale C and Paolesse R. J. Am. Chem. Soc. 2007; 129: 6688. d) Monti D, De Rossi M, Sorrenti A, Laguzzi G, Gatto E, Stefanelli M, Venanzi M, Luvidi L, Mancini G and Paolesse R. Chem. Eur. J. 2010; 16: 860.

5. a) Štěpánek $P$, Dukh $M$, Šaman D, Moravcová J, Kniežo L, Monti D, Venanzi M, Mancini G and Drašar P. Org. Biomol. Chem. 2007; 5: 960. b) Monti D, Venanzi M, Gatto E, Mancini G, 
Sorrenti A, Štepánek P and Drašar P. New J. Chem. 2008; 32: 2127.

6. Zelenka K, Trnka T, Tišlerová I, Monti D, Cinti S, Naitana ML, Schiaffino L, Venanzi M, Laguzzi G, Luvidi L, Mancini G, Nováková Z, Šimák O, Wimmer Z and Drašar P. Chem. Eur. J. 2011; 17: 13743. For important related works see: a) D'Urso A, Fragalà ME and Purrello R. Chem. Commun. 2012; 48: 8165. b) Occhiuto I, De Luca G, Villari V, Romeo A, Micali N, Pasternack RF and Monsù Scolaro L. Chem. Commun. 2011; 47: 6045. c) Mammana A, D'Urso A, Lauceri R and Purrello R. J. Am. Chem. Soc. 2007; 129: 8062. d) Tsuda A, Alam MdA, Harada T, Yamaguchi T, Ishii N and Aida T. Angew. Chem. Int. Ed. 2007; 46: 8198. e) Escudero C, Crusats J, Díez-Pérez I, El-Hachemi Z and Ribó JM. Angew. Chem. Int. Ed. 2006; 45: 8032. f) Zhang Y, Chen P and Liu M. Chem. Eur. J. 2008; 14: 1793.

7. a) Lettieri R, Monti D, Zelenka K, Trnka T, Drasar P and Venanzi M. New. J. Chem. 2012; 36: 1246. b) Zhylitskaya HA, Zhabinskii VN, Litvinovskaya RP, Lettieri R, Monti D, Venanzi M, Khripach VA and Drasar P. Steroids 2012; 77: 1169.

8. Ethirajan M, Patel NJ and Pandey RK. In Handbook of Porphyrin Sciences, Vol. 4, Kadish KM, Smith KM and Guilard R. (Eds.) World Scientific: London, 2010; Chapter 19, pp 249.

9. Brotherhood PR and Davis AP. Chem. Soc. Rev. 2010; 39: 3633. Gale PA. Chem. Commun. 2011; 47: 82.

10. Thomas S and Milanesi L. J. Am. Chem. Soc. 2009; 131: 6618.

11. Monti D, Stefanelli M, Raggio M, Colozza N, Venanzi M, Lettieri R, Luvidi L, Laguzzi G, Bonacchi S, Weber D, Prodi L, Di Natale C and Paolesse R. J. Porphyrins Phthalocyanines 2012; 15: 1209.

12. a) Hembury GA, Borovkov VV and Inoue Y. Chem. Rev. 2008; 108: 1. b) Paolesse R, Monti D, La Monica L, Venanzi M, Froiio A, Nardis S, Di Natale C, Martinelli E and D'Amico A. Chem. Eur. J. 2002; 8: 2476 .

13. Li C, Zhang H, Jiang D and Yang Q. Chem. Commun. 2007; 547.
14. Dukh M, Šaman D, Lang K, Pouzar V, Černý I, Drašar P and Král V. Org. Biomol. Chem. 2003; 1: 3458.

15. Allenmark S. Chirality 2003; 15: 409, and references therein.

16. a) Berova $\mathrm{N}$ and Nakanishi K. In Circular Dichroism. Principles and Applications, $2^{\text {nd }}$ edn., Berova N, Nakanishi K and Woody RW. (Eds.) John Wiley \& Sons: New York, 2000; pp 337. b) Pescitelli G, Gabriel S, Wang Y, Fleischhauer J, Woody RW and Berova N. J. Am. Chem. Soc. 2003; 85: 3173.

17. Pasternack RF, Gibbs EJ, Collings PJ, dePaula JC, Turzo LC and Terracina A. J. Am. Chem. Soc. 1998; 120: 5873 .

18. The term extinction is of more appropriate use than absorbance, because of the presence of scattering contribution to UV-vis bands. See, for example; Micali N, Mallamace F, Castriciano M, Romeo $\mathrm{A}$ and Monsù Scolaro L. Anal. Chem. 2001; 73: 4958.

19. a) Pasternack RF, Fleming C, Herring S, Collings PJ, dePaula JC, DeCastro J and Gibbs EJ. Biophys. J. 2000; 79: 550. b) Castriciano MA, Romeo A and Monsù Scolaro L. J. Porphyrins Phthalocyanines 2002; 6: 431. c) Witten TA and Sander LM. Phys. Rev. Lett. 1981; 47: 1400.

20. This is referred as a Diffusion Limited Cluster Cluster Aggregation mechanism (DLCCA), and has been reported to be operative, in aggregation of water soluble tetrapyrrolic macrocycles, either at high porphyrin concentration, or at low $\mathrm{pH}$ conditions. a) Monsù Scolaro L, Castriciano MA, Romeo A, Mazzaglia A, Mallamace F and Micali N. Physica A 2002; 304: 158. b) Micali N, Villari V, Castriciano MA, Romeo A and Monsù Scolaro L. J. Phys. Chem. B 2006; 110: 8289.

21. Dimroth parameter $(\Delta E)$ is the electronic transition energy of a selected zwitterionic molecule in a given solvent, relative to hexane. The values give a good correlation for the overall properties of the solvents. Jones RAY. Physical and Mechanistic Organic Chemistry, Cambridge University Press: Cambridge, UK, 1984; Chapter 5, pp 94. 